\title{
Prediction of Blood-Brain Barrier Penetration of meta-/para-Alkoxyphenylcarbamic Acid Esters Bearing Substituted N-Phenylpiperazine Fragment
}

\section{Lubica Havranova Sichrovska ${ }^{1}$, Ivan Malik ${ }^{1}$, Eva Sedlarova ${ }^{1}$, J ozef Csollei ${ }^{1,2}$, Lukas Stanzel $^{1}$, J ana Galisinova ${ }^{1}$ and Fils Andriamainty ${ }^{1}$}

\author{
${ }^{1}$ Department of Pharmaceutical Chemistry, Faculty of Pharmacy, Comenius University, Odbojárov 10, 83232 \\ Bratislava, Slovak Republic \\ ${ }^{2}$ Department of Chemical Drugs, Faculty of Pharmacy, University of Veterinary and Pharmaceutical Sciences, \\ Palackého 1-3, 61242 Brno, Czech Republic
}

Received: October 08, 2013; Accepted: December 15, 2013; Published (web): June 29, 2014

\begin{abstract}
The present study deals with blood-brain barrier $(B B B)$ passive penetration of the substances labelled as 7a-7d and chemically referred to as 1-[3-(Y-alkoxyphenylcarbamoyloxy)-2-hydroxypropyl]-4-(2-methylphenyl) piperazinium chlorides. Following their chemical structures, they could be classified as prospective $\alpha-/ \beta$-adrenoceptor blockers. Such groups are known, among others, by their adverse reactions on central nervous system due to their transport across the $B B B$. The lipophilicity as the main parameter of the $B B B$ permeability predictions is presented by the values of partition coefficient which was experimentally estimated using shake-flask method in two different partitions, i.e. in octan-1-ol/buffer and cyclohexane/buffer as well. The in silico models which were used are based on the correlation between the $\log B B$ and the $\Delta \log P$ readouts (the $\log P$ value estimated in octan-1-ol/buffer minus the one estimated in cyclohexane/buffer) whereby $\log B B$ is primary transfer marker for such compounds entering brain from blood. Besides the $\log B B$ outputs, some other molecular physicochemical descriptors have to be generated. According to the results obtained by using Young, Kaliszan, Kelder, Clarks, Pan, Abraham, Feher and van de Waterbeemd models, probably none of the currently investigated compounds will permeate across the $B B B$.
\end{abstract}

Key words: $\alpha$-/ $/ \beta$-Blockers, slkoxyphenylcarbamates, partition coefficient, blood-brain barrier, lipophilicity

\section{INTRODUCTION}

$\beta$-Adrenergic receptor blockers $(\beta$-blockers; $\beta$ ARBs) are in general well tolerated and commonly used for variety of cardiovascular and noncardiovascular disorders. Aimed group of the drugs is efficacious with relatively few accompanying side effects. Besides such fact, some of the $\beta$-ARBs are connected with serious CNS undesirable effects. Two key factors determine the extent of penetration through the blood-brain barrier. These are partition coefficient and the ability to bind to plasma proteins as well. ${ }^{1}$ Current study is concerned only with partition coefficient. In terms of pharmacokinetics, relatively lipophilic $\beta$-ARBs cross the $B B B$ more easily than the hydrophilic ones which can cause

Correspondence to: Lubica Havranova Sichrovska Tel.: +421-2-50117224; Fax: +421-2-50117100;

E-mail: lubica.sichrovskafaf@gmail.com

Dhaka Univ. J. Pharm. Sci. 13(1): 7-14, 2014 (June) pharmacodynamic diversity within this therapeutic group and which leads to differences in clinical practice in the end. ${ }^{2}$ The most frequently occurred undesirable side effects on CNS are headaches, depression, panic, sleeping disorders, nightmares and hallucinations as well which may occur due to the binding to CNS adrenergic and/or serotonergic receptors or via non-specific membrane stabilizing effects. $^{3}$ For example, last three side effects mentioned above are related to a depressed melatonin secretion. Norepinephrine stimulates synthesis and releasing of melatonin via $\beta_{1^{-}}$and $\alpha_{1}$-adrenergic receptors (ARs). It has been proved that $\beta$-ARBs have been able to reduce the production of melatonin via specific inhibition of $\beta_{1}$-AR. ${ }^{4}$ For the evaluated series of the compounds labelled as $\mathbf{7 a - 7 d}$ could be assumed such dualistic effect on both $\alpha$ - as well as $\beta$ ARs. Integrated 2-hydroxypropane-1,3-diyl fragment is primarily responsible for $\beta_{1}$-antagonistic activity 
whereas (substituted) N-phenylpiperazin-1-yl fragment controls their activity as vasodilatants.

\section{MATERIALS AND METHODS}

Characterization of the evaluated compounds. Synthesis, basic physicochemical properties as well as spectral characterization of the substances under the study 7a-7d were previously published in paper. ${ }^{5}$

The SMILES codes. The SMILES (Simplified Molecular-Input Line-Entry Specification) notification is a comprehensive chemical language (a typographical method using printable characters) with its own rules which specifies molecules and reactions using ASCII characters to represent atom and bond symbols. The result is a line notation which comes into being from two-dimensional drawn pictures. ${ }^{6}$ The ALOGPS program which has been used for the generation of SMILES strings is Java based server and it is one of the main parts of the VCCLAB site. The studied molecules were at first converted into the SMILES codes (in the form of bases and corresponding salts with hydrochloric acids) from their 2D-structures drawn in Java molecular editor and according to these codes specific parameters could be calculated. ${ }^{7}$

Estimation of partition coefficients. The logarithm of partition coefficients (the $\log P_{\exp }$ data) were estimated experimentally in two mediums, octan-1-ol/phosphate buffer $\left(\log P_{\text {expo }}\right)$ and cyclohexane/phosphate $\left(\log P_{\text {expc }}\right)$ buffer, using wellknown and generally accepted shake-flask method. Lipophilic phase was represented by octan-1$\mathrm{ol} /$ cyclohexane and the aqueous one by phosphate buffer with $\mathrm{pH}=7.4$ prepared from disodium hydrogenphosphate, p.a. (Slavus, Slovak Republic) with $c=0.2 \mathrm{~mol} \cdot \mathrm{l}^{-1}$ and pure citric acid (Chemapol, Czech Republic) with $c=0.1 \mathrm{~mol} \cdot \mathrm{l}^{-1}$. The process of the $\log P_{\text {expo }}$ estimation was described in detail within the paper. ${ }^{5}$ The $\log P_{\operatorname{expC}}$ readouts were estimated by applying the method described below. The amount $0.0020 \mathrm{~g}$ of particular investigated compound was dissolved in $50 \mathrm{ml}$ of phosphate buffer with $\mathrm{pH}=7.4$ in volumetric flask. The volume of $5 \mathrm{ml}$ of basic solution was weakened with phosphate buffer into $10 \mathrm{ml}$ volumetric flask. The absorbance of such solution was measured $\left(A_{1}\right)$. After adding $0.5 \mathrm{ml}$ of cyclohexane (Mikrochem, Slovak Republic), the system was shaken and the absorbance $\left(A_{2}\right)$ of aqueous phase was taken by the wavelength of second absorption maximum. Partition coefficient value(s) was (were) derived from the equations 1-3:

$$
\begin{aligned}
& P_{\exp C}=\frac{(1000 \times g)-\left(a \times c_{\mathrm{H}_{2} \mathrm{O}} \times M_{r}\right)}{b \times c_{\mathrm{H}_{2} \mathrm{O}} \times M_{r}} \\
& c_{\mathrm{H}_{2} \mathrm{O}}=\frac{A_{2}}{\varepsilon} \\
& \varepsilon=\frac{A_{1}}{c}
\end{aligned}
$$

where $g$ is the weight of studied compound in grams in $10 \mathrm{ml}$ of measured solution, $a$ is number of mililiters of aqueous phase, $b$ is number of mililiters of cyclohexane, $M_{\mathrm{r}}$ is molecular weight of studied compound, $\mathrm{cH}_{2} \mathrm{O}$ is amount of inspected compound in aqueous phase after shaken, $c$ is concentration of measured solution expressed in $\mathrm{mol} / \mathrm{l}$ units.

The prediction of partition coefficient in system octan-1-ol/water. Partition coefficient in system octan-1-ol/,,water" was calculated for the substances 7a-7d using two specific methods, the CLOGP 4.0 (an integral part of Bio-Loom 1.5 software) and MLOGP (an integral part of ALOGPS applet) which are based on different algorithms. The CLOGP 4.0 method is based on principles of constructionism developed by Hansch and Leo. ${ }^{8}$ Fragmental system consists of exactly measured log $P$ data of a small set of simple molecules whereby the other values were derived. This method is rule-based fragmental conception of isolating carbon $\left(s p^{3}\right.$ carbon with at least two bonds linked directly to two another carbons). Consequently correction for branching was applied. 200 Fragments and 25 correction factors were defined. Chou and Jurs ${ }^{9}$ adapted this method for computational use and called it CLOGP. The version 4.0 was upgraded with so-called FRAGCALC algorithm which is based on 600 fragments containing only aliphatic or aromatic bonds. ${ }^{10}$ 
The MLOGP approach reflects the relationship between the structure of compound or topological indices and the $\log P$ data. The set of 1230 organic molecules including general aliphatic, aromatic and heterocyclic structures which contains $\mathrm{C}, \mathrm{H}, \mathrm{N}, \mathrm{O}, \mathrm{S}$ $\mathrm{P}, \mathrm{F}, \mathrm{Cl}, \mathrm{Br}$ and $\mathrm{I}$ atoms were used for deriving 13 parameters that are the basis for calculating $\log P$ values according to Moriguchi: ${ }^{11}$

$$
\begin{aligned}
& \text { MLOGP }=-1.041+1.244(\mathrm{CX})^{0.6}-1.017(\mathrm{NO})^{0.9}+ \\
& 0.406(\mathrm{PRX})-0.145(\mathrm{UB})^{0.8}+0.511(\mathrm{HB})+ \\
& 0.268(\mathrm{POL})-2.215(\mathrm{AMP})+0.912(\mathrm{ALK})- \\
& 0.392(\mathrm{RNG})-3.684(\mathrm{QN})+0.474(\mathrm{NO} 2)+ \\
& 1.582(\mathrm{NCS})+0.773(\mathrm{BLM})
\end{aligned}
$$

Particular parameters presented witin the equation (4) are described in article. ${ }^{11}$

Distribution coefficient value(s) calculation. As the neutral and ionic species are diversely polarised, the $\log P$ readout of ionisable compounds is $\mathrm{pH}$ dependant. ${ }^{12}$ General contribution of ionised and unionised form of compound in both phases water and non-aqueous is described as distribution coefficient $(D)$. Providing that only neutral species are present in non-aqueous phase, for acidic compounds value of $\log D$ can be calculated according to the relationship if the activity corrections are neglected: ${ }^{13}$

$$
\log D=\log P-\log \left(1+10^{p H-p K_{a}}\right)
$$

The calculation of some molecular descriptors used in particular models for the $B B B$ penetration. Some important molecular properties as molecular (topological) polar surface area (TPSA), molecular volume and number of hydrogen bond acceptors $(n \mathrm{ON})$ have to be generated. Using interactive property calculator Molinspiration Cheminformatics (Slovak Republic), they were obtained and summarized for both basic and salty forms of studied molecules applying the SMILES codes generated before. ${ }^{14}$

Molecular (topological) polar surface area (TPSA). Such descriptor is defined as a sum of fragment contributions of polar atoms and their hydrogens attached. It is a quick fragmental method, which is called topological PSA. The TPSA assigns also relatively good to blood-brain barrier penetration, intestinal absorption and transport properties. Particular fragment contributions were determined by least squares fitting to the single conformer three-dimensional PSA for 34810 drugs from the World Drug Index. According to this model, 43 polar fragments centered over C-, N-, P-, S-atoms were determined. ${ }^{15}$

Molecular volume. The volume of a compound is given by a sum of group contribution of particular fragments, which correspond to real threedimensional volume. They were evaluated on the basis of set of 12000 molecules. Calculated volume is expressed in cubic Angstroems. ${ }^{16}$

Hydrogen bond acceptors (nON). Hydrogen bonds have importance in determining the interaction of drug with receptor. The simplest descriptor describing hydrogen bond is an indicator variable which has the value 1 if molecule or its substituent is able to create a hydrogen bond and value 0 if not. The $\mathrm{OH}-, \mathrm{NH}_{2}$ - and $\mathrm{COOH}$-groups have the value 1 for their donor and also acceptor ability whereas $\mathrm{OCH}_{3}{ }^{-}, \mathrm{N}\left(\mathrm{CH}_{3}\right)_{2^{-}}$and $\mathrm{COOCH}_{3}$-groups have for donor ability the value 0 and for the acceptor one the value $1 .^{17}$

The $\log$ BB values and in silico methods for the BBB penetration. The parameter of $\log B B$ is a common measure of the $B B B$ penetration degree and it is defined as the ratio of steady-state total concentration of investigated compound in the brain $\left(C_{\text {brain }}\right)$ to that in the blood $\left(C_{\text {blood }}\right):^{18}$

$\log B B=\frac{C_{\text {brain }}}{C_{\text {blood }}}$

The aim of current research was to calculate log $B B$ values applying commonly used models and to determine whether or not will the studied molecules permeate through the $B B B$. Generally, they are not based on classic quantum chemical descriptors from 3D-drug modelling, but they are set up on physicochemical properties and specific molecular descriptors. The first in silico model for prediction 
$B B B$ permeation was Young model. ${ }^{19}$ It is based on good correlation between the $\log B B$ and the $\Delta \log P$ outputs whereby the permeability increases with lower hydrogen-bonding ability:

$\log B B=0.889-0.485 \times \Delta \log P$

$n=20, r=0.831, s=0.439, F=40.2$

Kaliszan et al. developed a model based on the Young's one in which they took into account also molecular weight of compounds: $:^{20}$

$\log B B=-0.088+0.272 \times \Delta \log P-0.00112 \times M_{r} n$ $=33, r=0.947, s=0.126, F=131.1$

Kelder explained the role of PSA during penetration process of substances from blood to brain: ${ }^{21}$

$\log B B=1.330-0.032 \times P S A$

$n=45, r=0.840, F=229.0$

Clark used in his first model only PSA as a determinant, which was not applicable for the compounds without PSA (e.g. nonpolar): ${ }^{22}$

$\log B B=-0.016 \times P S A+0.550$

$n=57, r=0.819, s=0.455, F=229.0$.

From that reason it was necessary to implement another descriptor, which will distinguish non-polar substances. After an integration of the CLOGP value into the equation model B was suggested: ${ }^{22}$

$\log B B=0.139-0.148 \times P S A+0.152 \times C L O G P$

$n=55, r=0.790, s=0.350, F=95.8$

Using the MLOGP method instead of the CLOGP one, resulting model $\mathrm{C}$ provided slightly different statistic coefficients: $:^{22}$

$\log B B=0.131-0.145 \times P S A+0.172 \times M L O G P$

$n=55, r=0.770, s=0.370, F=86.0$

Pan's method was based on the division of substances into the clusters according to their chemical structure. This method is quite easy to use but it dismissed some statistic parameters: ${ }^{23}$ $\log B B=0.064+0.200 \times \log P_{\exp O}-0.00502 \times M_{r}$

$n=55, r=0.770, s=0.370, F=86.0$

Abraham derived a relationship for the calculating $\log B B$ value which come from a solvatation equation used to analyze solubility of gases and vapours in water, blood and other biological liquids: ${ }^{24}$

$\log B B=0.119+0.350 \times \log P_{\exp O}-0.00502 \times M_{r}$ $n=53, r=0.852, s=0.363, F=66.2$

Hydrogen bonding ability represented by $n_{\text {acc }}$ (number of atoms which are able to accept hydrogen bonds) was for Feher model given below essential: $:^{25}$

$\log B B=0.4275-0.3873 \times n_{\text {acc }}+0.1092 \times \log P_{\exp O}-0.0017 \times P S A$ $n=61, r=0.854, s=0.424, F=51.0$

Last model used within current paper was based on Young's set of molecules. van de Waterbeemd found out that the $\log B B$ value can be calculated by an implementation of $P S A$ and molecular volume $V_{\mathrm{m}}$ into the equation: ${ }^{26}$

$\log B B=-0.021 \times P S A-0.003 \times V_{m}+1.643$

$n=20, r=0.835, s=0.448, F=19.5$

\section{RESULTS AND DISCUSSION}

The equilibrium of distribution substances between blood and brain is given by a ratio of steady-state concentrations of the compounds in brain and in blood or plasma. In form of algorithms, it is defined as $\log B B$. The $B B B$ is described as the specialized set of specific capillary endothelial cells, which main function is to protect brain from malign agents, toxins and viruses which can be present in blood circulation. The $B B B$ can inhibit penetration of therapeutic agents into the brain but it has also the main role in supplying the brain with nutritive substances. In contradistinction to systemic circulation it's cells are characterized by a low degree of pinocytosis and membrane fenestration and that is the reason why exchange of substances between blood and brain is realized by transcellular way, i.e. by passive diffusion. The $B B B$ 
represents an enzyme barrier with higher concentrations of enzymes in brain microcapillaries. It also disposes of specific efflux transporters such as P-glycoprotein or another typical efflux mechanisms such as multi resistance protein or breast cancer resistant protein. Despite the assumption that passive diffusion through $B B B$ is the most important process of permeation, more and more scientist support the idea that actively mediated transport and influx/efflux can be even more important. ${ }^{27}$

The aim of current paper was to predict the margin of permeation of the compounds with incorporated $\mathrm{N}$-phenylpiperazine moiety, chemically
1-[3-(Y-alkoxyphenylcarbamoyloxy)-2--hydroxypropyl]-4-(2-methylphenyl)piperazinium chlorides (Table 1), through $B B B$ as potential drugs with supposed multireceptor activity. The descriptors used in specific models for the $B B B$ permeation were calculated for both forms of studied molecules, i.e. for the bases and the salts as well. The term base(s) represents molecule in which the nitrogen atom of piperazin-1,4-diyl skeleton is 3-bond (unprotonated) whereas the term salt(s) represent(s) the monochloride(s) whereby in this case the nitrogen atom is 4-bond as positive charge carrier.

Table 1. General characterization of investigated compounds 7a-7d.

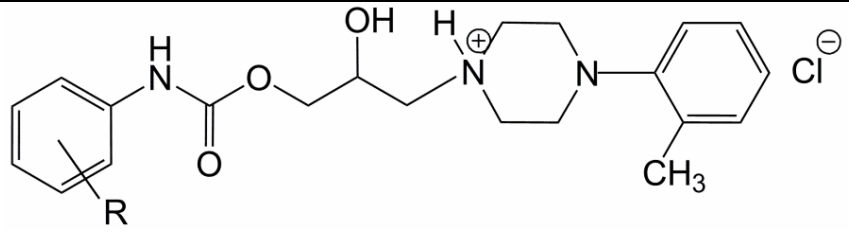

\begin{tabular}{ccccc}
\hline Entry & $R$ & Formula & $M_{\mathrm{rB}}$ (Base) & $M_{\mathrm{rS}}$ (Salt) \\
\hline $\mathbf{7 a}$ & $3-\mathrm{OCH}_{3}$ & $\mathrm{C}_{22} \mathrm{H}_{30} \mathrm{ClN}_{3} \mathrm{O}_{4}$ & 399.49 & 435.95 \\
$\mathbf{7 b}$ & $3-\mathrm{OC}_{2} \mathrm{H}_{5}$ & $\mathrm{C}_{22} \mathrm{H}_{32} \mathrm{ClN}_{3} \mathrm{O}_{4}$ & 413.52 & 449.98 \\
$\mathbf{7 c}$ & $4-\mathrm{OCH}_{3}$ & $\mathrm{C}_{22} \mathrm{H}_{30} \mathrm{ClN}_{3} \mathrm{O}_{4}$ & 399.49 & 435.95 \\
$\mathbf{7 d}$ & $4-\mathrm{OC}_{2} \mathrm{H}_{5}$ & $\mathrm{C}_{22} \mathrm{H}_{32} \mathrm{ClN}_{3} \mathrm{O}_{4}$ & 413.52 & 449.98 \\
\hline
\end{tabular}

Table 2. The SMILES codes of evaluated molecules generated for the form of base (B) and salt (S).

\begin{tabular}{|c|c|}
\hline Entry & SMILES \\
\hline $7 \mathbf{a B}$ & $\mathrm{C} 1=\mathrm{C}(\mathrm{OC}) \mathrm{C}=\mathrm{CC}=\mathrm{C} 1 \mathrm{NC}(\mathrm{OCC}(\mathrm{CN} 3 \mathrm{CCN}(\mathrm{C} 2=\mathrm{C}(\mathrm{C}) \mathrm{C}=\mathrm{CC}=\mathrm{C} 2) \mathrm{CC} 3) \mathrm{O})=\mathrm{O}$ \\
\hline $7 \mathrm{aS}$ & $\mathrm{C} 1=\mathrm{C}(\mathrm{OC}) \mathrm{C}=\mathrm{CC}=\mathrm{C} 1 \mathrm{NC}(\mathrm{OCC}(\mathrm{C}[\mathrm{N}+] 3([\mathrm{H}]) \mathrm{CCN}(\mathrm{C} 2=\mathrm{C}(\mathrm{C}) \mathrm{C}=\mathrm{CC}=\mathrm{C} 2) \mathrm{CC} 3) \mathrm{O})=\mathrm{O}$ \\
\hline $7 \mathbf{b B}$ & $\mathrm{C} 1=\mathrm{C}(\mathrm{OCC}) \mathrm{C}=\mathrm{CC}=\mathrm{C} 1 \mathrm{NC}(\mathrm{OCC}(\mathrm{CN} 3 \mathrm{CCN}(\mathrm{C} 2=\mathrm{C}(\mathrm{C}) \mathrm{C}=\mathrm{CC}=\mathrm{C} 2) \mathrm{CC} 3) \mathrm{O})=\mathrm{O}$ \\
\hline $7 \mathrm{bS}$ & $\mathrm{C} 1=\mathrm{C}(\mathrm{OCC}) \mathrm{C}=\mathrm{CC}=\mathrm{C} 1 \mathrm{NC}(\mathrm{OCC}(\mathrm{C}[\mathrm{N}+] 3([\mathrm{H}]) \mathrm{CCN}(\mathrm{C} 2=\mathrm{C}(\mathrm{C}) \mathrm{C}=\mathrm{CC}=\mathrm{C} 2) \mathrm{CC} 3) \mathrm{O})=\mathrm{O}$ \\
\hline $7 \mathrm{cB}$ & $\mathrm{C} 1=\mathrm{CC}(\mathrm{OC})=\mathrm{CC}=\mathrm{C} 1 \mathrm{NC}(\mathrm{OCC}(\mathrm{CN} 3 \mathrm{CCN}(\mathrm{C} 2=\mathrm{C}(\mathrm{C}) \mathrm{C}=\mathrm{CC}=\mathrm{C} 2) \mathrm{CC} 3) \mathrm{O})=\mathrm{O}$ \\
\hline $7 \mathrm{cS}$ & $\mathrm{C} 1=\mathrm{CC}(\mathrm{OC})=\mathrm{CC}=\mathrm{C} 1 \mathrm{NC}(\mathrm{OCC}(\mathrm{C}[\mathrm{N}+] 3([\mathrm{H}]) \mathrm{CCN}(\mathrm{C} 2=\mathrm{C}(\mathrm{C}) \mathrm{C}=\mathrm{CC}=\mathrm{C} 2) \mathrm{CC} 3) \mathrm{O})=\mathrm{O}$ \\
\hline $7 \mathrm{~dB}$ & $\mathrm{C} 1=\mathrm{CC}(\mathrm{OCC})=\mathrm{CC}=\mathrm{C} 1 \mathrm{NC}(\mathrm{OCC}(\mathrm{CN} 3 \mathrm{CCN}(\mathrm{C} 2=\mathrm{C}(\mathrm{C}) \mathrm{C}=\mathrm{CC}=\mathrm{C} 2) \mathrm{CC} 3) \mathrm{O})=\mathrm{O}$ \\
\hline $7 \mathrm{dS}$ & $\mathrm{C} 1=\mathrm{CC}(\mathrm{OCC})=\mathrm{CC}=\mathrm{C} 1 \mathrm{NC}(\mathrm{OCC}(\mathrm{C}[\mathrm{N}+] 3([\mathrm{H}]) \mathrm{CCN}(\mathrm{C} 2=\mathrm{C}(\mathrm{C}) \mathrm{C}=\mathrm{CC}=\mathrm{C} 2) \mathrm{CC} 3) \mathrm{O})=\mathrm{O}$ \\
\hline
\end{tabular}

As the most significant property is considered the partition coefficient estimated experimentally in two various lipohydrophilic systems, i.e. in octan-1ol/buffer $\left(\log P_{\text {expo }}\right)$ and cyclohexane/buffer $(\log$ $\left.P_{\operatorname{expC}}\right)$ as well. In octan-1-ol/buffer medium were estimated the values similar for meta- and paramethoxy derivatives (3.44 and 3.47, respectively; Table 3) just like for the meta- and para-ethoxy ones (3.60 and 3.65, respectively; Table 3). In the medium made up from cyclohexane and buffer were determined higher readouts for the substances containing the substituent $R$ in meta-position (1.66 and 1.73, respectively; Table 3). One of the most important experimental parameter used within current paper is the value of $\Delta \log P_{\text {expO-expC }}$ characterizing distribution of the substances between two system with different lipophilic phase. As expected, higher outputs were acquired for ethoxy derivatives (Table 3). 
The majority of therapeutically used drugs are ionisable substances which can be ionised into several degrees by the physiological pH. Positive and negative charged molecules are much more polar than the neutral ones. Therefore the degree of polarisation shows a significant influence on the lipophilicity of ionisable substances. The distribution coefficient is characterized as an effective lipophilicity measured by specific $\mathrm{pH}$ considering inner lipophilicity and the degree of ionisation. ${ }^{28}$ Observed values are at interval from 1.31 to 3.42 in both used mediums. According to calculated results it can be assumed that investigated compounds will penetrate partially through the $B B B$ (Table 3 ).

Polar surface area (PSA) is a prediction parameter of drug transport properties and it is formed of atoms which can accept hydrogen bonds hydrogen bond acceptor $(n \mathrm{ON})$. The value of PSA is defined as a sum of surfaces of polar atoms (usually oxygens and nitrogens) and hydrogens attached directly to these heteroatoms. ${ }^{15}$

Molecules with PSA higher than $140 \AA^{2}$ are usually absorbed badly from stomach and gastrointestinal tract whereas PSA readout about 60$70 \AA^{2}$ indicates relatively good gastrointestinal absorption as well as a passage through the $B B B$. The outputs of PSA for studied compounds in their basic form are lower of a contribution of hydrogen atom attached to nitrogen atom in form of salt. As in both cases, the values of PSA are higher than $70 \AA^{2}$ so it can be expected that the evaluated substances not to cross the $B B B$ (Table 4).

Table 3. Some experimentally estimated and calculated parameters of the lipophilicity for inspected set of the compounds 7a-7d.

\begin{tabular}{cccccc}
\hline Entry & $\log P_{\operatorname{expO}}$ & $\log P_{\operatorname{expC}}$ & $\Delta \log P$ & $\log D_{\mathrm{o} / \mathrm{w}}$ & $\log D_{\mathrm{c} / \mathrm{w}}$ \\
\hline $\mathbf{7 a}$ & 3.44 & 1.66 & 1.78 & 3.23 & 1.45 \\
$\mathbf{7 b}$ & 3.60 & 1.73 & 1.87 & 3.42 & 1.55 \\
$\mathbf{7 c}$ & 3.47 & 1.62 & 1.85 & 3.20 & 1.35 \\
$\mathbf{7 d}$ & 3.65 & 1.60 & 2.05 & 3.36 & 1.31 \\
\hline
\end{tabular}

$\Delta \log P=\Delta \log P_{\operatorname{expO}-\operatorname{expC}}$

Table 4. Molecular descriptors generated by Molinspiration Cheminformatics, Bio-Loom 1.5 and ALOGPS applets for evaluated set of the compounds $7 \mathbf{a}-7 \mathrm{~d}$.

\begin{tabular}{|c|c|c|c|c|c|c|c|c|c|}
\hline \multirow{2}{*}{ Entry } & \multirow{2}{*}{$P S A_{\mathrm{B}}$} & \multirow{2}{*}{$P S A_{\mathrm{S}}$} & \multirow{2}{*}{$V_{\mathrm{mB}}$} & \multirow{2}{*}{$V_{\mathrm{mS}}$} & \multirow{2}{*}{$n \mathrm{ON}$} & \multicolumn{2}{|c|}{ CLOGP 4.0} & \multicolumn{2}{|c|}{ MLOGP } \\
\hline & & & & & & Base & Salt & Base & Salt \\
\hline $7 a$ & 74.27 & 75.47 & 378.312 & 381.425 & 7 & 3.53 & 3.73 & 1.58 & -2.10 \\
\hline $7 b$ & 74.27 & 75.47 & 395.114 & 398.227 & 7 & 4.06 & 4.26 & 1.80 & -1.89 \\
\hline $7 c$ & 74.27 & 75.47 & 378.312 & 381.425 & 7 & 3.53 & 3.73 & 1.58 & -2.10 \\
\hline 7d & 74.27 & 75.47 & 395.114 & 398.227 & 7 & 4.06 & 4.26 & 1.80 & -1.89 \\
\hline
\end{tabular}

$P S A_{\mathrm{B}} / P S A_{S}=$ polar surface area calculated for bases/salts, $n \mathrm{ON}=$ hydrogen-bond acceptors (bases), $V_{\mathrm{mB}} / V_{m \mathrm{~S}}=$ calculated molecular volume for bases/salts

As the passage across the $B B B$ is realized through passive transport, among lipophilicity, molecular volume as well as charge are considered some of the most important factors. Small molecules can cross the $B B B$ easily while the relatively bulkier ones do not cross the barrier at all. The data about molecular volume were used lately in van de Waterbeemd and Kansy model. ${ }^{29}$ Higher values are related to the compounds in form of salt (Table 4).

The partition coefficient in octan-1-ol/,,water" medium can be also calculated using in silico methods. Two approaches, CLOGP 4.0 and MLOGP, have been chosen within current paper. In the series of the substances under the study $\mathbf{7 a - 7 d}$ were generated equivalent values for corresponding metaand para-alkoxy positional isomers (Table 4).

The values of the $\log B B$ for the most of drugs used in practise range from -2.000 to $1.000 .^{30}$ The substances with the $\log B B$ data higher than 0.300 cross the $B B B$ easily. ${ }^{30}$ On the other hand, the compounds which showed lower $\log B B$ readout than -1.000 indicated their low concentration in the brain. 
In present study, the $B B B$ penetration of the compounds 7a-7d has been predicted by applying ten models based on different principals. Using Young and Kaliszan models, the calculated $\log B B$ data were not higher than 0.300 (Table 5).
The values were either negative or just in two cases positive (for the compound 7a in Young model, for 7d in Kaliszan model, respectively). In remaining models, the $\log B B$ data were negative and not higher than -0.564 . Even most of them were under the limit of -1.000 .

Table 5. Calculated values of $\log B B$ using Young, Kaliszan and Kelder models.

\begin{tabular}{ccccccc}
\hline \multirow{2}{*}{ Entry } & \multicolumn{2}{c}{ Young } & \multicolumn{2}{c}{ Kaliszan } & \multicolumn{2}{c}{ Kelder } \\
\cline { 2 - 7 } & Base & Salt & Base & Salt & Base & Salt \\
\hline 7a & - & 0.026 & -0.051 & -0.569 & -1.047 & -1.085 \\
7b & - & -0.018 & -0.043 & -0.083 & -1.047 & -1.085 \\
$\mathbf{7 c}$ & - & -0.008 & -0.032 & -0.073 & -1.047 & -1.085 \\
$\mathbf{7 d}$ & - & -0.105 & 0.006 & -0.034 & -1.047 & -1.085 \\
\hline
\end{tabular}

Table 6. Calculated values of $\log B B$ using Clark $(A, B, C)$ and Pan models.

\begin{tabular}{ccccccccc}
\hline \multirow{2}{*}{ Entry } & \multicolumn{2}{c}{ Clark (A) } & \multicolumn{2}{c}{ Clark (B) } & \multicolumn{2}{c}{ Clark (C) } & \multicolumn{2}{c}{ Pan } \\
\cline { 2 - 9 } & Base & Salt & Base & Salt & Base & Salt & Base & Salt \\
\hline 7a & $-0,638$ & $-0,658$ & $-10,316$ & $-10,464$ & $-10,366$ & $-11,173$ & $-0,585$ & $-0,606$ \\
7b & $-0,638$ & $-0,658$ & $-10,236$ & $-10,383$ & $-10,329$ & $-11,137$ & $-0,553$ & $-0,574$ \\
$\mathbf{7 c}$ & $-0,638$ & $-0,658$ & $-10,316$ & $-10,464$ & $-10,366$ & $-11,173$ & $-0,579$ & $-0,600$ \\
$\mathbf{7 d}$ & $-0,638$ & $-0,658$ & $-10,236$ & $-10,383$ & $-10,329$ & $-11,137$ & $-0,543$ & $-0,564$ \\
\hline
\end{tabular}

Table 7. Calculated values of $\log B B$ using Abraham, Feherand van de Waterbeemd models.

\begin{tabular}{ccccccc}
\hline \multirow{2}{*}{ Entry } & \multicolumn{2}{c}{ Abraham } & \multicolumn{2}{c}{ Feher } & \multicolumn{2}{c}{ van de Waterbeemd } \\
\cline { 2 - 7 } & Base & Salt & Base & Salt & Base & Salt \\
\hline 7a & -0.682 & -0.865 & -2.786 & -2.788 & -1.052 & -2.730 \\
7b & -0.697 & -0.880 & -2.803 & -2.805 & -1.102 & -2.780 \\
$\mathbf{7 c}$ & -0.742 & -0.855 & -2.789 & -2.791 & -1.052 & -2.730 \\
$\mathbf{7 d}$ & -0.679 & -0.862 & -2.808 & -2.810 & -1.102 & -2.780 \\
\hline
\end{tabular}

In conclusion, following the obtained results is can be assumed that the $B B B$ will be impassable for all of currently investigated compounds $\mathbf{7 a - 7 d}$ which could be classified as potential $\alpha-/ \beta$-AR blockers without any serious undesirable effects on CNS.

\section{ACKNOWNLEDGEMENT}

The authors are very grateful to Slovak Grant Agency for Science for supporting by the VEGA Grant Project No. 1/0039/12.

\section{REFERENCES}

1. Neil-Dwyer, G., Bartlett, J., McAinsh, J. and Cruickshank, J.M. 1981. $\beta$-Adrenoceptor blockers and the blood brain barrier. Br. J. Clin. Pharmac. 11, 549-553.
2. McAinsh, J. and Cruickshank, J.M. 1990. Beta-blockers and central nervous system side effects. Pharmacol. Ther. 46 , 163-197.

3. Lama, P.J. 2002. Systematic adverse effects of betaadrenergic blockers: An evidence-based assessment. Am. J. Ophthalmol. 134, 749-760.

4. Fares, A. 2011. Night-time exogenous melatonin administration may be a beneficial treatment for sleeping disorders in beta blocker patients. J. Cardiovasc. Dis. Res. 2, 153-155.

5. Malik, I., Sedlarova, E., Andriamainty, F., Galisinova, J., Csלllei, J. and Vanco, J. 2011. Synthesis and basic physicochemical properties of 1-[3-(Y-alkoxyphenylcarbamoyloxy)-2--hydroxypropyl]-4-(2-methylphenyl)piperazinium chlorides. Čes. slov. Farm. 60, 137-143.

6. Information available at http://www.daylight.com/dayhtml/ doc/ theory/theory.smiles.html. 
7. Tetko, I.V., Gasteiger, J., Todeschini, R., Mauri, A., Livingstone, D., Ertl, P., Palyulin, V.A., Radchenko, E.V., Zefirov, N.S., Makarenko, A.S., Tanchuk, V.Y. and Prokopenko, V.V. 2005. Virtual Computational Chemistry Laboratory - design and description. J. Comput.-Aided Mol. Design 19, 453-463.

8. Leo, A.J., Jow, P.Y.C., Silipo, C. and Hansch, C.J. 1975. Calculation of hydrofobic constant $(\log \mathrm{P})$ from $\pi$ - and $\mathrm{f}$ constants. Med. Chem. 18, 865-868.

9. Chou, J.T. and Jurs, P.C. 1979. Computer assisted computation of partition coefficients from molecular structures using fragment constants. J. Chem. Inf. Comput. Sci. 19, 172-178.

10. Mannhold, R. and van de Waterbeemd, H. 2001. Substructure and whole molecule approaches for calculating $\log$ P. 2001. J. Comput.-Aided Mol. Design 15, 337-354.

11. Moriguchi, I., Hirono, S., Liu, Q., Nakagome, I. and Matsushita, Y. 1992. Simple method of calculating octanol/water partition coefficient. Chem. Pharm. Bull. 40, 127-130.

12. Kah, M. and Brown, C.D. 2008. Log D: Lipophilicity for ionisable compounds. Chemosphere. 72, 1401-1408.

13. Smith, D.A., van de Waterbeemd, H. and Walker, D.K. 2001. Pharmacokinetics and Metabolism in Drug Design: Method and Principles in Medicinal Chemistry. Wiley-VCH Verlag, Weinheim, p. 5.

14. Information available at http://www.molinspiration.com/ services/properties.html.

15. Information available at http://www.molinspiration.com/ services/psa.html.

16. Information available at http://www.molinspiration.com/ services/volume.html.

17. Smith, H.J. and Williams, H. 2006. Smith and Williams' Introduction to the Principles of Drug Design and Action, $4^{\text {th }}$ Ed. Taylor \& Francis Group, Boca Raton, p. 720.

18. Fu, X., Song, Z. and Liang, W. 2005. A predictive model for blood-brain barrier penetration. Internet Electron. J. Mol. Des. 4, 737-750.

19. Young, R.C., Mitchell, R.C., Brown, T.H., Ganellin, C.R., Griffiths, R., Jones, M., Rana, K.K., Saunders, D., Smith, I.R., Sore, N.E. and Wilks, T.J. 1988. Development of a new physicochemical model for brain penetration and its application to the design of centrally acting $\mathrm{H}_{2}$ receptor histamine antagonists. J. Med. Chem. 31, 656-671.
20. Kaliszan, R. and Markuszewski, M. 1996. Brain/blood distribution described by a combination of partition coefficient and molecular mass. Int. J. Pharm. 145, 9-16.

21. Kelder, J., Grootenhuis, P.D., Bayada, D.M., Delbressine, L.P. and Ploemen, J.P. 1999. Polar molecular surface as a dominating determinant for oral absorption and brain penetration of drugs. Pharm. Res. 16, 1514-1519.

22. Clark, D.E. 1999. Rapid calculation of polar molecular surface area and its application to the prediction of transport phenomena. Pharm. Sci. 88, 815-821.

23. Pan, D., Iyer, M., Liu, J., Li, Y. and Hopfinger, A.J. 2004. Constructing optimum blood brain barrier QSAR models using a combination of 4D-molecular similarity measures and cluster analysis. J. Chem. Inf. Comput. Sci. 44, 2083-2098.

24. Abraham, M.H. and Weathersby, P.K. 1994. Solubility of gases and vapors in biological liquids and tissues. J. Pharm. Sci. 83, 1450-1456.

25. Feher, M., Sourial, E. and Schmidt, J.M. 2000. A simple model for the prediction of blood-brain partitioning. Int. J. Pharm. 201, 239-247.

26. van der Waterbeemd, H. and Kansy, D. 1992. Hydrogenbonding capacity and brain penetration. Chimia 46, 299-303.

27. Mensch, J., Oyarzabal, J., Mackie, C. and Augustijns, P. 2009. In vivo, in vitro and in silico methods for small molecule transfer across the BBB. J. Pharm. Sci. 98, 44294468.

28. Wang, G.P. and He, W. 2011. Hydrophilic Interaction Liquid Chromatography (HILIC) and Advanced Application. CRC Press, Boca Raton, p. 1-26.

29. Kaznessis, N.Y. 2005. A review of methods for computational prediction of blood-brain partitioning. Curr. Med. Chem. 5, 1-7.

30. Hutter, M. 2003. Prediction of blood-brain barrier permeation using quantum chemically derived information. J. Comput.Aided Mol. Design 17, 415-433. 